\title{
Humanitarian support in a denial of access context: emergent strategies at the interface of humanitarian and sovereign law
}

\author{
Erwin Biersteker ${ }^{1 *}$ (D), Julie Ferguson ${ }^{1,2}$, Peter Groenewegen ${ }^{1}$ and Kees Boersma ${ }^{1}$
}

\begin{abstract}
The principles of international humanitarian law $(\mathrm{HL})$ have evoked considerable debate in the practice of humanitarian support, particularly in terms of emerging tensions with sovereign (national) law. Drawing on organization studies, we examine the emergent strategies aimed at resolving the ambiguous legal context in which humanitarian support operations in a conflict context are embedded. Our analysis of two missions revealed two types of emergent strategies, namely network and negotiation strategies, differentiated by particular contextual dimensions. We extend the humanitarian law debate by showing the strategic interplay between the operational humanitarian context and international humanitarian principles, thereby connecting the fields of international law and organization science.
\end{abstract}

Keywords: International humanitarian law, Sovereign law, Emergent strategy, Organization sciences, Denial of access, Conflict

\section{Introduction}

"Applying the humanitarian principles of humanity, impartiality, neutrality, and independence in a relevant manner in a concrete setting is a constant challenge for humanitarian organizations" (Labbé and Daudin 2015).

Contemporary armed conflicts are characterized by a tension between humanitarian law and the notion of state sovereignty (Bartels 2018; Kaldor 2012). This tension can be attributed to at least two reasons. First, conflicting parties nowadays are sometimes more interested in "the enterprise of conflict" rather than simply winning or losing (Kaldor 2012). In other words, private companies are often engaged in combat situations with related incentives for economic gain prolonging conflicts (Leander 2005), as in Iraq. Second, the concept of sovereignty has changed in

\footnotetext{
* Correspondence: e.biersteker@vu.nl

'Department of Organization Sciences, Vrije Universiteit Amsterdam, Amsterdam, The Netherlands

Full list of author information is available at the end of the article
}

this new setting, with irregular armed troops instigating war (Malantowicz 2013). For instance, ISIS rationalized its armed uprising against Syrian and Iraqi troops, terrorizing, and killing civilians unwelcome to their cause of establishing its caliphate.

Humanitarian norms represent a crucial regulatory framework for access and protection of citizens, all the more when they suffer undue hardship where states withhold or fail to provide "supplies essential to their survival" (Newman 2014). However, practice shows that states sometimes-purposefully or inadvertently-design strategies to deny humanitarian organizations access. This creates a conflicting legal framework where states on the one hand adopt principles of international humanitarian law (IHL) as a means to regulate crossborder conflict, while on the other hand they draw on their sovereign rights to deny within-country permission of access (Labonte and Edgerton 2013).

Indeed, where sovereign states are unable or unwilling to provide aid to their citizens, humanitarian 
organizations gain significance. Nevertheless, the roles and responses of humanitarian organizations in face of the ambiguity of IHL versus sovereign law have been given only marginal attention. For instance, scholars have shown that due to ethical and safety considerations, humanitarian organizations are hesitant to engage in humanitarian support operations when these risk breaching important IHL principles; at the same time, this is sometimes the only and inevitable means to realize their objectives (Maisel 2015; Broussard et al. 2019). It therefore remains unclear how humanitarian organizations can conduct their critical services in a context where sovereignty and IHL collide. Nonetheless, this is of critical importance as a path toward providing safe and legally sound humanitarian aid.

In response to this need, this study provides two contributions. First, we unravel the position of international humanitarian law in the ambiguous legal context of sovereign denial-of-access. Second, we explain the process of strategy-making in humanitarian organizational practice, in view of these legal considerations. In doing so, we respond to calls for a deeper understanding of the micro-processes in coping with the challenges of humanitarian practices (Broussard et al. 2019; Starr and Van Wassenhove 2014; Clarke and Campbell 2020). In this manner, we reconstruct how IHL is reflected in decision-making during daily humanitarian operations, drawing on a perspective of emergent strategies.

Emergent strategies are shaped by operational decisions made at an ad hoc basis by professionals in the situation in which they operate (Vaara and Whittington 2012). Particularly, humanitarian organizations working in a denial-of-access-context have a certain leeway to conduct their operations, as their strategies often emerge by necessity and adapt to the operational context, in contrast to more formally prescribed strategies. Nevertheless, at this operational level, IHL principles remain a critical operational framework, as legitimization for the operation (Gasser 1998) or as a guideline during operational practices (Mačák 2015). By exploring strategic choices at an operational level in this context, we provide an understanding of how the context of conflicts influences the humanitarian professionals responds while they navigate between sovereign law and IHL in their local strategic practices. Therefore, this paper examines the research question: how do humanitarian professionals strategically respond to contemporary conflict in a local context, at the interface between sovereign law and IHL principles? To respond to this question, we compared the practices of professionals engaged in two humanitarian missions, providing humanitarian support in a context of denial of access.

In what follows, we first introduce the theoretical background to our study, positioned between the scholarly fields of international law and organization sciences; we then show how humanitarian professionals in a denial of access context draw on IHL principles in their organizational processes; and finally, we discuss the implications of our study for theory and practice.

\section{Theory \\ Guiding principles of international law regarding humanitarian support}

Humanitarian support is guided by three key principles: first, the humanity principle; second, the impartiality and neutrality principle (described together as the "moral ideal and ethical guidelines") (Labbé and Daudin 2015); and third, the sovereignty principle. These principles apply in circumstances of international and noninternational armed conflicts, whereby invoking specific references to international legal instruments depends on the nature of the conflict in question, the nature of the parties to the conflict, and determine the question on who has control over the territory. The first principle of humanity, widely accepted among humanitarian organizations (Fast 2015), is the ideal or "essential principle from which all other principles are derived" (Pictet 1979). The humanity principle is reflected in numerous treaty provisions, most notable in the Martens Clause and Art. 3 of the 4th Geneva-Convention of 1949, interpreted by international and domestic tribunals, and consistently practiced by states during conflicts. In essence the principle "forbids the inflicting of all suffering, injury, or destruction not necessary for achieving the legitimate purpose of conflict" (ICRC, 2015, 6). Moreover, customary international law states that "parties to the conflict must allow and facilitate rapid and unimpeded passage of humanitarian relief for civilians in need"1(also see Henckaerts and Doswald-Beck 2005). It means that humanitarian support cannot be seen as an unlawful intervention, if it is conducted in accordance with humanitarian principles (ICJ, 1986). However, the principle is not without controversy: for instance, it leaves undefined how the principle should be exactly applied in view of the specific circumstances of a conflict (Fast 2015). Even so, the humanity principle can be considered the main motivation and legitimization of humanitarian practice.

Second, the impartiality and neutrality principle, which is currently used as a synonym hereafter impartiality (see Mačák 2015), is considered as the other main moral ideal and ethical guideline constituting humanitarian support (Labbé and Daudin 2015). These principles are codified in Art. 70 Additional Protocol I (1970), Art. 18 Additional Protocol II, and customary international

${ }^{1}$ International Committee of the Red Cross. Rule 55 of Customary IHL. 
law. Impartiality presumes unbiased humanitarian support provisioning, whereby "actions are solely guided by needs, proportionate to the degree of suffering and prioritized on the basis of urgency" (Beeckman 2015). As no humanitarian organization can cover all needs of all victims, this proportionality helps to set priorities at an operational level. Hence, within daily operations, the impartiality principle is an essential ethical guideline for the application of international humanitarian law in a particular context. Applying this principle is challenging, in part due to the growing use of information and communication technologies (ICT) in identifying citizens in need of aid, which inadvertently excludes citizens without access to such systems from support (Raymond and Card 2015).

Third, the sovereignty principle is key in guiding humanitarian organizations' strategic operational choices. This principle relates to the extent to which relief action must be consented to and the conditions under which relief actions must be conducted. The sovereignty principle articulates that humanitarian support operations are subject to the constent of the parties to the conflict pursuant to Art. 70(1) of Additional Protocol I of 1977 and Art. 18 of Additional Protocol II. Thus, without government consent, humanitarian organizations in practice can rarely provide the support the situation requires. However, during a situation where, for example, a lack of humanitarian support amounts to civic starvation, there is no valid reason to be invoked by any party to justify a denial of access (Art. 54(1) Additional Procotol I; Art. 14 Additional Protocol II; Customary International Law as reflected by ICRC, 2005). Therefore, the principles of humanity and impartiality principles can drive humanitarian organizations to provide lawful support regardless of the state's consent, in line with the circumstances and their moral and ethical guidelines (Labbé and Daudin 2015). Under certain circumstances, the latter two principles thus override the sovereignty principle, implying that humanitarian operations are conducted without authorization. In extreme circumstances, such operations can then be frustrated (Labonte and Edgerton 2013), if sovereign rules determine there is no necessity for the international support, or if a state decides national prerogatives should be prioritized. Acting as a "rogue humanitarian organization," the legality of the operational practices then remains unclear, even when these can sometimes be justified retrospectively. The sovereignty principle is therefore a salient legal hurdle, and a key tension in humanitarian support.

IHL principles help humanitarian organizations to make strategic choices and thereby shape their operational judgment. As such, IHL and the sovereignty principles are important guidelines for navigating the ever-changing, complex conflicts that such organizations are confronted with. In other words, there is no preferred or prescribed solution to be derived directly from specific IHL principles. Indeed, given the ambiguities and tensions described above, strategic choices call for weighing of different humanitarian principles "with consistency [ ], but also intelligence and creativity" (Labbé and Daudin 2015). In other words, humanitarian principles require interpretation (Abdelmagid et al. 2019). This leaves professionals of humanitarian organizations in a particularly vulnerable situation, often working under great duress and stress due to ongoing conflicts, while navigating an ambiguous legal situation. Evidently, it is of great importance that humanitarian organizations gain a clearer understanding of how their strategic choices might be improved, as a means to alleviate this vulnerability. Organization science, whereby strategic decision-making is a key debate, is useful for addressing this need.

\section{Developing organizational responses: emergent strategies} This study adopts an emergent perspective to analyze how humanitarian organizations make strategic choices when providing humanitarian support in a denial of access context. The strength of this perspective-also known in organization sciences as "strategy as practice" (Vaara and Whittington 2012) or "micro-strategizing" (Johnson et al. 2003) - is that it explains how strategymaking is enabled and constrained by prevailing organizational and societal practices. In other words, this perspective distinguishes between formal and emergent strategies, while focusing on the intertwined strategic relationship between these two forces in practice (Jegers 2002; Ogliastri et al. 2016). Formal strategies are predefined by organizational management, aimed at maximizing organizational performance and managing different stakes (Morrison and Salipante 2007). In contrast, emergent strategies are not formally planned but emerge during actual organizational practice.

In the context of our study, emergent strategies represent a continuous balancing of local stakes through the guidance of IHL. Emergent strategy is therefore a concept that encapsulates the daily flexibility that is required in a highly volatile environment, which the unclear legal framework within a conflict context represents (Ogliastri et al. 2016). However, how humanitarian organizations go about this balancing act while drawing on IHL, so far remains largely unexplored. This is nonetheless an important field of inquiry, given the unstable and unpredictable context that humanitarian organizations operate in. Thus, by analyzing humanitarian operations from an emergent perspective, we advance understanding of how humanitarian organizations navigate the complex landscape of IHL principles in a legally ambiguous context 
that conflict comprises. Next, we introduce what operating in such a context implies for humanitarian organizations.

\section{Denial of access: community-based initiatives, ICT, and advocacy}

In the context of a denial of access, close collaboration with the local community is an essential condition for humanitarian support. Such collaboration often takes form by way of community-based initiatives (CBIs), comprising semi-formalized or informal social networks (Comfort 2007) whereby citizens actively self-organize, in an effort to respond to needs that government authorities are unable or unwilling to fulfill (Jeong 2005). Practitioners and scholars alike argue for investing in the development or support of CBIs in response efforts during disasters (Boersma et al. 2016; Kapucu et al. 2010), as a means to guarantee the continuation of social life and to mitigate international disasters (Boin and Lodge 2016; Mac Ginty and Richmond 2013). These CBIs are often aimed at both employing and protecting their social networks in response to humanitarian crises. Furthermore, collaboration with CBIs is an important resource for humanitarian organizations to achieve their goals and keep their personnel safe.

In a complementary development, ICTs, specifically encrypted social media platforms, are deployed to an increasing degree by humanitarian organizations as a useful means to enable information exchange (Duffield 2016; Starbird and Palen 2011) while tapping into the self-organizing capacity of CBIs. For instance, the emergent networks following crises in Haiti and Nepal generated a crucial map over an open-source, SMS-enabled platform, which guided humanitarian organizations toward the most pertinent humanitarian needs (Wolbers et al. 2016). While such initiatives are useful in many crises, they are essential when humanitarian organizations are unable to enter the territory where initiatives are located, for instance due to restrictions imposed by sovereignty principles.

However, the use of ICTs can also potentially weaken the application of humanitarian principles, by fundamentally changing humanitarian operations into hybrid organizational-civilian efforts. For example, the impartiality principle can be compromised when a humanitarian organization seeks to digitally connect people and include them in their operations, at the expense of those not connected to the internet (Cardia et al. 2017; Mulder et al. 2016). Furthermore, the absence of minimum standards or professional ethics for the provision of ICT and the lack of legal guidelines for balancing the reliance on CBIs to obtain and provide information and infrastructure fosters inequality of the legal application of IHL (Raymond and Card 2015). Consequently, this unequal application of IHL will further erode the position of IHL within humanitarian support context. This issue is likely to be prevalent in cases of a denial of access through sovereign law and where connections with the local community are limited to those facilitated through the internet.

In sum, providing humanitarian support is challenging due to the conflicting legal principles that affect operations. Humanitarian principles are a crucial enabler for access to a humanitarian crisis field and subsequent negotiations in a relatively neutral manner (Kyazze 2015). However, the strategic organizational processes guiding these practices in a denial of access context remains unclear and calls for clarification, in an effort to make a volatile work environment somewhat more manageable. In the case study that follows, we illustrate how humanitarian professionals navigate this tension in practice.

\section{Case study}

Given our interest in understanding how humanitarian organizations strategically develop response mechanisms to the tension between IHL and the sovereignty principle, we examined the strategic choices of two humanitarian missions-both part of one organization-in a conflict ridden state. We adopted qualitative methods to obtain a detailed picture of their practices while gaining insight into the interplay between the legal principles and the strategy adopted. We inductively interpreted our data with an intent to build theory, so we selected our cases based on their theoretical value (Marshall 1996). A contrasting case study is used to provide an explorative overview response mechanisms within the field of our interest (Gómez and Kuronen 2011). In this case, we study the mechanisms that humanitarian teams employ when responding to the the legal tension they experience on their humanitarian mission. By examining two teams within one humanitarian organization, we isolated the relationship between the contextual environment and the strategic responses of the teams. Moreover, we control for the organization's policies that could shape the strategic response of operational teams to legal principles. A contrasting case study within that organizational context emphasizes the different conditions under which teams operate and thereby reveals response mechanisms in relation to context-specific situations (Hantrais 1999). This type of case study unravels common mechanisms that can be used to understand the dynamics between humanitarian organizations and their legal contentious position. In other words, our findings are likely to be of use to other cases with similar criteria to our selection (Eisenhardt and Graebner 2007; Eisenhardt 1989).

The criteria underlying our case selection were first, the humanitarian professionals are part of a mission operating locally in a nation state affected by conflict; 
second, they are faced by a denial of access to enter the crisis area by the sovereign government; and third, they (attempt to) connect with CBIs, moderated by ICTs. Our first contact with the organization was a convenience sample through our own network, and comprised a former Head of Mission with vast experience in humanitarian war situations and a broad network of relevant respondents. We conferred with her to verify that our snowball sampling yielded the most appropriate respondents, i.e., to ensure a well-rounded, heterogeneous selection of perspectives on the context and the strategies employed. In this manner, we identified further respondents, all of whom were connected to humanitarian missions that met the selection criteria in interaction with the former Head of Mission and using a snowballing selection technique (Atkinson and Flint 2001) (further detailed below).

\section{Methods}

We carried out 13 interviews with 11 humanitarian professionals (see Table 1), all of whom were directly involved in providing humanitarian support in this humanitarian crisis context. All professionals were team members of two missions, hosted by the same humanitarian organization. Our study focused on how these professionals generated emergent strategies in response to the challenges they encountered in their practices; therefore, these professionals as individual actors comprise our level of analysis.

Respondents were very difficult to reach, due to the sensitivity of the cases and the geographical distance between the researcher and the respondents, so a snowball technique (Atkinson and Flint 2001) allowed us to make use of our respondents' knowledge and to connect us to the most relevant subsequent respondents. This technique risks leading to a homogeneous interview sample of interviewees, missing case complexity (Browne 2005). However, each of the mission teams sampled was small,

Table 1 List of respondents

\begin{tabular}{lll}
\hline Respondent & Function & Mission \\
\hline 0.0 & Former Head of Mission & Lead organization \\
1.1 & Field Coordinator & Besieged area \\
1.2 & Head of Mission & Besieged area \\
1.3 & Former Head of Mission & Besieged area \\
1.4 & Head coordination medical staff & Besieged area \\
1.5 & Outreach Worker & Besieged area \\
2.1 & Field Coordinator & Border closure \\
2.2 & Head of Mission & Border closure \\
2.3 & Former Head of Mission & Border closure \\
2.4 & Humanitarian Officer & Border closure \\
2.5 & Medical Doctor & Border closure \\
\hline
\end{tabular}

comprising around five to six humanitarian professionals, and we were able to interview most of them, equally divided over both missions both in numbers and function. This yielded a well-rounded perspective and reduced methodological risks. In this manner, we obtained a useful dataset to understand which emergent strategies had been employed by each team.

The interviews were conducted using a semistructured interview protocol comprising questions related to the emergent strategies in dealing with the casespecific sovereignty-IHL tension in a denial of access context. More specifically, we investigated the professional's current operational tasks and mission responsibilities; the professional's relationship with their direct stakeholders; their awareness and willingness to support $C B I s$; and the implications of humanitarian principles for their operations. When a new topic emerged from the data, we used it in subsequent interviews to verify its significance for other interviewees. All interviews were recorded and transcribed.

\section{Analytical methods}

This study started with an inductive approach by using basic guiding theoretical concepts, such as international humanitarian principles, CBIs, ICTs, and advocacy practices. These concepts helped develop a theoretical outline and to create sensitizing concepts for coding data (Bowen 2006). The interviews were first coded in vivo, with codes directly related to interviewees' answers, thereby staying close to the respondents' meaning (Gioia et al. 2013) and promoting a proficient level of reliability (Bowen 2006). We then identified which in vivo codes could be combined into broader themes, which we interpreted by using our theoretical background. In this manner, we sought to make sense of the complexity of the context vis-à-vis the emergent strategies deployed in the different missions. In this manner, we were able to distinguish four key contextual elements that enabled two emergent strategies, as we now explain.

\section{Findings: emergent humanitarian strategies in denial of access contexts}

\section{Setting the scene}

The mission was set in a nation state where insurgents and their allies who sought to overthrow the ruling government were fighting state forces. Different parts of the country were affected by the civil war, so different missions were deployed by the humanitarian organization to neighboring countries to see where they could provide humanitarian support most effectively. The national government denied any humanitarian access from Western origin, such as European or American humanitarian organizations. This study follows two missions in two different neighboring countries, to observe how the 
involved professionals strategically responded to the legal predicament of navigating both sovereign law and humanitarian principles. In our first case, the organization was faced with a severe humanitarian situation whereby civilians in a besieged area were in desperate need of basic needs, made inaccessible by the government. The second case comprised a border area containing refugees of the conflict but whereby, for security reasons, the adjacent nation-state disallowed any traffic across their borders to access the humanitarian crisis field.

\section{The emergent strategic choices of the humanitarian organization}

Our research revealed two different strategies through which the missions sought to resolve the legal tensions in practice. That is, in the besieged context professionals primarily adopted a network strategy, while professionals in the border closure mission predominantly implemented a negotiation strategy. The basic premise of the network strategy is that the humanity principle is prioritized over the sovereignty and impartiality principle. Moreover, this strategy is characterized by professionals' connection with informal organizations, their personal involvement, a "cowboy mentality" to risk evaluation, and their trust in CBIs. The negotiation strategy prioritizes the sovereignty principle and is characterized by humanitarian professionals' engagement with the formal organization, their professional involvement, and their "safety first" mentality. Below, we describe these findings in more detail.

\section{Case 1: deploying a network strategy in the besieged area}

In the context of the besieged area, the humanitarian professionals primarily deployed a network strategy that was predicated on their own justification to act. The network strategy involved forging or drawing on productive social relations as a means to provide humanitarian support in the besieged area. This sometimes called for opportunistic behavior, whereby professionals connected with conveniently placed parties and whereby a cowboy mentality was sometimes needed to enable the necessary access. In such contexts, the humanity principle, rather than the sovereignty principle, was the primary driver of humanitarian support.

Networking the sovereignty principle: questioning the central authority The team of this mission comprised three foreign humanitarian professionals and two locals who were excluded by the ruling regime in the provision of basic human needs. The humanitarian professionals that were locally familiar had close contacts with other, often informally organized humanitarians as part of CBIs. These CBIs were often organized in response to the besiegement, by regional administrative committees or owners of private hospitals and enterprises. All their contacts opposed the ruling regime and their initiatives were aimed at mitigating the harm inflicted by the government. Initiatives, for example, included hospitalized basements, cars transformed into mobile health clinics, or groups smuggling medical and food supplies. In this process, all the humanitarian professionals within the team consistently justified their support to these initiatives by delegitimizing the ruling government, emphasizing the protracting oppression and their violation of international law. For instance, they argued that the regime does not care about its people, but continuously oppressed it, as shown in the ongoing government besiegement. A respondent explained:

"If you live in [country] for four decades under this oppression and insult against your basic rights, when you have the chance to fight this regime to let it be removed, we didn't feel we were courageous, not at all; we had to do this' (Respondent 1.4)."

This explanation shows the respondent's justification for providing humanitarian support, namely to oppose the ruling government and putting sovereignty aside. Sharing this motive, another respondent argued that the criminalization of doctors helping citizens in need "is crazy" (Respondent 1.1), while another suggested that the government had "lost its mind" and therefore could no longer be taken seriously in legal terms (Respondent 1.5).

Humanitarian professionals also explained that through its violation of IHL and human rights, the government in fact de-legitimated itself, and that it was their responsibility as humanitarian professionals to alleviate the wrongdoing. For example, the alleged chemical weapons attack by the government further motivated the professionals to act, as Respondent 1.5 explained: "How can we take their authority legally seriously when they breach every human right possible?". Another suggested: "We have to help, but it is not easy. You cannot publicly provide [these political activists] with [more medical] equipment, because the government bombs it. It has a huge impact, and even if the people know there is a hospital to go to, they are afraid they regime will bomb this" (Respondent 1.1).

Overall, the interviews revealed that the violations of IHL and human rights law conducted by the government led humanitarian professionals to wonder what the base of the authority is, but seemed nonetheless to strengthen them in their motivation to proceed with their dangerous work. 
Networking the humanity principle: forging trusted relations The humanity principle was the most prevalent principle guiding the network strategy, driving humanitarian professionals to provide support to people affected by the conflict. This often occurred by way of local CBIs.

Connections with CBIs were often established through previously established friendships or professional networks, which have shown to be paramount in deploying this strategy. A few humanitarian professionals were formerly highly-ranked local citizens, so they could deploy a well-established network to engage in contact with multiple scattered networks. A respondent explained that the humanitarian organization deliberately hired locals to get better access to the field: "they selected people who have connections and many contacts inside the country, that's why they could have access to all areas" (Respondent 1.3). Those contacts subsequently became:

"the eyes and ears on the ground [ ] Because we are far away from the area, we do not have the opportunity to smuggle people into the area, or provide training, or to manage the security of our people. So we rely on the expertise of the people in the field" (Respondent 1.2).

While contacts were important, trust was critical in order to provide humanitarian support on this scale.

The interplay between trust and the network was described by a respondent as "very very important," particularly when the humanitarian organization operated in sending supplies to the besieged area. For instance, when there was a request for medical supplies, the reputation of the requester played a critical role. Trust was never fully taken-for-granted, and the organization drew on triangulation mechanisms such as different ICT-tools to gauge the trustworthiness of a person on an ongoing basis. As one respondent described:

"For example, we send some [contacts] to the [initiative] and we ask them to give us feedback about the 'initiative'. There are also focal points on the ground and we ask them to do field visit reports. Then we have a report containing certain information that is needed to assess this initiative. By triangulation of this report with other information, we can estimate the level of trust of people or [initiatives]" (Respondent 1.4).

Thus, other local contacts were of great importance to verify the information and to evaluate whether a person or initiative could be trusted. ICT-tools were an essential means to support this form of triangulation and helped ensure that the networks underlying humanitarian operations were trustworthy.

\section{Networking the impartiality principle: providing} non-discriminatory support The humanitarian professionals chose to provide a significant amount of support remotely through CBIs, but at the same time they recognized that this could jeopardize the impartiality of their support efforts. Respondents explained that impartiality was important, as a means to legitimize their operation. It showed that they tried not to exclude their support to any party involved in the conflict. Although the large scale of their operation made the professionals vulnerable to inadvertent contact with warlords or local initiators in need of support themselves.

One respondent explained that the situation thus sometimes called for a cowboy mentality, in that "some things we do are questionable, but ultimately we support the people on the ground. We sometimes have to take a risk" (Respondent 1.5). Besides, another respondent added "many humanitarian professionals are locals, so they are willing to take more risks [with their social network] in order to get things done" (Respondent 1.1). The risk was not only associated with security, but also with liability and a loss of legitimacy.

To gain access to a humanitarian crisis field occupied by warlords, the humanitarian professionals we spoke to were aware they sometimes navigated on thin ice. One respondent explained: "we do have contact with [warlords] but I cannot talk about it too much, as we might bring people and our organization in danger. For me, that is a dilemma" (Respondent 1.2). More concretely, this dilemma was that to provide as much support as possible in line with the impartiality principle, those in need of support could also include people of dubious reputation in the conflict. This was a dilemma that the professionals found difficult to manage, but an inevitable part of their humanitarian work.

Sometimes humanitarian professionals deployed the impartiality principle in an opportunistic manner as a means to gain the necessary support for their work. For example, one respondent explained:

"When we have no other contacts in a specific area, and the [community initiators] do not provide impartial access to their services, we will first try to establish contact in that specific region without stopping our support, but when we have new contacts, we use these contacts to force the [initiators] to provide impartial access" (Respondent 1.2).

Similarly, another respondent shared: "we will force militias to provide impartial support, or otherwise we will shut down our operation there and start up a new 
one via our contacts. We want to have access for everybody" (Respondent 1.5). The impartiality principle was then used as an argument to widen the scope and gain access to the people in need, drawing on the social network and the cowboy mentality to leverage access and facilitate operations.

In sum, our analysis showed that the humanity principle was most often invoked when adopting a network strategy. The impartiality principle was less prevalent and was used as a tool to provide more support to more people. The professionals strategically delegitimized the sovereignty of the ruling government within their own teamto enact their humanitarian support.

\section{Case 2: Implementing a negotiation strategy in the border closure}

In the context of the border closure, the humanitarian professionals deployed a negotiation strategy as a means to realize their humanitarian objectives. The negotiation strategy involved an ongoing balancing act for the humanitarian professionals, maintaining the flexibility to act where possible, while pursuing the primacy of their humanitarian objective in the midst of different interests. This sometimes involved making compromises or accepting suboptimal solutions. In this context, the sovereignty principle was the primary driver of humanitarian support. However, the humanity and impartiality principle also played an important role in the negotiations and served an important role in ensuring professionals could conduct their work as safely as possible.

\section{Negotiating the sovereignty principle: acknowledging} security considerations The mission in the border closure area comprised fully of non-local professionals engaged by formal organizations. The mission was aimed at helping citizens stuck in a spontaneously coalesced refugee settlement near the border. Because the state's army was not capable or willing to provide safety and security to the humanitarian professionals to provide humanitarian support, violating Rule 31 customary international law of ICRC and Art. 71 lid 2 Additional Protocol I, the organization needed to find a way to safely enter the refugee settlement. The organization attempted to enter the area by hosting weekly coordinating meetings aimed at information sharing or joint goalsetting between organizations stationed in the area, such as representatives of the adjacent state army, the United Nations Refugee Agency (UNHCR) and the International Committee for the Red Cross (ICRC).

During these coordination meetings, humanitarian professionals negotiated with the army of the adjacent state to gain access to the people in order to provide aid. However, humanitarian professionals expressed their understanding of the army's stance in denying them full access to the field. As one respondent pointed out:

"Just imagine you being the head of the army and I want to get access to the camp. Your responsibility is to provide safety and security to me and your men. Because I am a humanitarian person, I have a higher risk of being abducted. So, your men have to accompany me, to provide safety. You cannot guarantee me and your men's security, so you won't do it. I can understand his point" (Respondent 2.1).

The quotation shows that the humanitarian professional is susceptible to the security argument of the army. Although the humanitarian professionals tried to push forward humanitarian principles during the negotiations, the national security argument always trumped the advocacy for humanitarian law, as described by another respondent:

"The governments that we negotiate with are quite clever, and more often than not they know these [IHL] rules and they know what can work in contrary action of them, while at the same time they would use a national security argument to trump all legal frameworks" (Respondent 2.2)

Given the significance of the army's security arguments, the humanitarian organization was driven to seeking other opportunities to support the needy population.

Negotiating the humanity principle: coping with suboptimal solutions During negotiations, the humanitarian organization, the third party army, UNHCR, and the ICRC came up with a solution that retained state sovereignty. That is, near the refugee settlement an international base was set up for the humanitarian staff of the currently studied organization and the ICRC, among others. In tranches, small selections of refugees could be transferred to this base for humanitarian support. Humanitarian professionals could also drive from the international base to the refugee settlements for a flash visit, under the supervision of the army. However, this solution was suboptimal as a means to provide support, as Respondent 2.2 explained: "For us [this solution] is a big problem, we have crossed many red lines, but now we can help some people, although it is not fully impartial. But we agreed upon operating in this base for now." This shows that the humanitarian organization emphasized the humanity principle as a primary motive, while not losing sight of impartiality as another leading IHL principle. 
Professionals also tried to connect with community workers tied to local CBIs within the border closure area, although they were often not familiar with these local go-betweens, as one respondent characterized:

"We don't know their [professional] background, they can say "I am a [professional]" but I am not sure if he or she is qualified, or not. However, I know that they're dealing with [clients], go see [clients] and they try to treat these [clients]. So let's say community workers can be [semi-professional], then everyone can become community workers after training, house workers. It's then possible that without [a professional background] you can be community worker, you just need to get some training to identify [clients]" (Respondent 2.5).

The unfamiliarity with the counterparts in the border closure area made it quite tricky for professionals to send supplies secretly or to accept their information uncritically. This was also based on their fear of people trying to take advantage of the situation:

"We do not send our supplies to them, because they could make a profit out of it, or send it to the wrong destination. We cannot monitor it effectively" (Respondent 2.1).

Although the humanitarian professionals were in daily contact with CBIs through WhatsApp, Viber, or Skype, the internet was an insufficient means to foster mutual trust. The humanitarian organization wanted to have full access to the humanitarian crisis field in order to become familiarized with these community workers, to build a relationship and provide more effective remote support in the current context and in the future. As a respondent asserted:

"If we have access, we can collect data better and find out the backgrounds of people. Now we don't know anything of them. With access, we can make lists and meet them face-to-face. So maybe then we can send goods" (Respondent 2.5).

The professionals were eager to provide more support, and safety concerns restricted their ability to extend their mission, as they repeatedly explained. For instance:

"Of course we would like to do more, but we cannot at this moment. [ ] it's like we have, we can't ask our staff, that people we work with in [country], to be more exposed to violence and travel to [the humanitarian crisis field], because it's not safe" (Respondent 2.4).
Thus, the routine was to stick to basic, remote, ICTenabled humanitarian support and by supporting people who came to the international base with army mediation. This was rather unsatisfactory for the humanitarian professionals but, as one respondent explained: "we are a humanitarian organization, so we have to live by the humanitarian principles in order to be called humanitarian" (Respondent 2.4). Thus, negotiating with the army was the only viable solution.

Negotiating the impartiality principle: seeking impartiality and safety During the negotiations, the impartiality principle proved a leading principle for humanitarian support. One respondent indicated:

"We are a humanitarian organization in the end, so the humanitarian principles are imperative. [ ] The main principle we are taking into consideration, when we are drafting our operational plans before starting negotiation with the army, is always based on impartiality" (Respondent 2.4).

The impartiality principle was considered a red flag that set the boundaries, helping to determine what was or was not negotiable as a means to provide humanitarian support. An example of such a red flag was the following scenario:

"If we get patients and we [ ] try to figure out where they are coming from, and then we realize they are all from one part of the camp, you know, only $40 \%$ of the camp is covered, only $40 \%$ of the 150 is covered, so that for us will be a red flag that you will have someone brokering access to certain people to get to us" (Respondent 2.1).

The humanitarian organization wanted to have access to the entire community and did not want to fuel any tribal tensions going on in the settlement. The impartiality principle also related to safety concerns during the negotiations, namely if the humanitarian organization actively provided humanitarian support to only a few tribes, they would have a high risk of being targeted by other tribes. One respondent explained: "we do not want to become party with one of the tribes. We need to be impartial" (Respondent 2.1).

In sum, the network strategy showed that sovereignty was an important principle in this context, as it set physical restrictions on where the humanitarian professionals could or could not go, and also contributed to other boundaries in their work. By respecting this principle, professionals were better able to negotiate a deal to gain access to the field with consent and therefore protection from the army controlling the area. The humanity and 
impartiality principles were of significance in ensuring these efforts could be done safely and fairly.

\section{Analysis: explaining the two strategies}

Our analysis shows that the emergent networking and negotiation strategies deploy different means to respond to the denial-of-access context and that inherently the sovereignty versus the humanitarian principles was gauged differently. In seeking to explain the strategic differences, we identified four key dimensions underlying the emergent strategies, namely first, the type of organization that humanitarian professionals engaged with; second, the motivation for engagement among professionals connected to third, their risk mentality; and fourth, the level of trust between the professionals and CBIs. We now describe each of these dimensions, and then show how they were combined to enable the formation of two different emerging strategies in weighing IHL and sovereignty principles.

\section{Organizational engagement}

We identified a distinction between the types of organizations that humanitarian professionals engaged with. These comprised on the one hand, engagements with other formal organizations, both humanitarian and other related organizations, such as offices specialized in human rights law; on the other hand, these comprised engagements with informal organizations, such as CBIs. In our study, the besieged area mission predominantly had contact with informal organizations, while the border closure mission predominantly engaged with formal organizations.

Contacts with formal organizations were often established by the humanitarian organization by drawing on legal arguments for providing humanitarian support, which sometimes resulted in negotiations about legal terms of humanitarian support rather than enacting it. In contrast, engagement with informal organizations (CBIs) often comprised of communications through (encrypted) ICTs, such as WhatsApp. These communications were intended for maintaining contacts toward gaining intelligence from the humanitarian crisis field. The conversations with informal organizations tended to be more practical in nature and were more related to the opportunities of providing humanitarian support.

\section{Motivation for engagement}

Among the humanitarian professionals we spoke to, some were personally involved with the conflict situation, while others were professionally engaged. For example, some professionals had personal contacts that had been tortured and killed by the government, which evidently added a personal dimension to their local involvement. This kind of involvement was dominant in the besieged area context. For example, one respondent commemorated:

"Three of my friends were arrested and two of these three were killed under torture on the first day they were arrested, although we didn't know they were killed at that time." (Respondent 1.4).

Alternatively, some humanitarian professionals were involved professionally, without any direct personal connection to the humanitarian crisis:

"I haven't seen any patients inside the camp. No, I haven't seen any single people, I haven't talked to any single person. In a few days, I go back to my country because I cannot do anything here." (Respondent 2.5)

Personal engagement led professionals to more readily adopt a networking strategy, while professional engagement evoked negotiation strategy. This is directly linked to the risk mentality encountered among professionals.

\section{Risk mentality}

We found that professionals' different motives to engage in a mission justified their strategic approach in the context. Where professionals were personally involved or affected by the conflict, we encountered a cowboy mentality, whereby humanitarians were willing to take more risk if this would allow them to provide help. To this end, they were more willing to strategically network as a means to realize their objectives. Alternatively, where professionals engaged in a mission primarily on a professional basis-and often deployed from overseas or other contexts-they tended to adopt a safety-first mentality. Such professionals were often less willing to take on risks, preferring to negotiate first and act second, as a means to ensure their safety.

\section{Trust}

The dimension of trust was mostly associated with the question as to whether the humanitarian organization could act safely while circumventing the sovereignty principle. It was not uncommon for CBIs to take advantage of the chaotic situation, so establishing a trusted relationship was a critical enabler for ensuring first aid products reached the people in greatest need. As one respondent explained: "we cannot be sure they (CBIs) just use us for their own benefit, [ ] in the camp it is the freedom of power and money. They can take the medications we send them and sell them for money" (Respondent 2.1). 
Table 2 The explanatory dimensions and the emergent strategies

\begin{tabular}{lll}
\hline & Network strategy & Negotiation strategy \\
\hline Organizational engagement & Informal organizations & Formal organizations \\
Motivation for involvement & Personal & Professional \\
Risk mentality & Cowboy mentality & Safety first \\
Trust in CBls & Strong trust & Weak trust \\
\hline
\end{tabular}

Our respondents recognized that trust was a crucial enabler for exchanging information and goods, and the extent to which this could be realized depended on familiarity with the CBIs. Within the negotiation strategy, the trust in local CBIs was low due to unreliable sources of information within the camp. Therefore sending humanitarian support clandestinely was not an option. In contrast, the network strategy utilized established relationships that facilitated trust building between the humanitarian professionals and CBIs. For instance, a native professional had known the community for years already, so required far less time to get humanitarian operations going. As she described:

"So, we adopt what they adopt for us, we start this channel and it's kind of snowballing via people we get introduced to, and we listen to them. They have a request and we don't think, but just do it for them" (Respondent 1.5).

Because of the taken-for-granted nature of the relationship, the mission was able to provide supplies easily, as a respondent explained: "[our organization] in general is trusted by the people when they were attacked. We give them money and supply them, and then we wait for a while" (Respondent 1.2).

Table 2 provides an overview of the explanatory dimensions that make sense of the emergent strategies as deployed by professionals in the two humanitarian missions.

\section{Discussion}

This study shows how humanitarian professionals adopt different strategic responses that emerge in a denial-ofaccess context, namely a network strategy and a negotiation strategy. Each of these emergent strategies, adopted in a context of conflict, reflects IHL principles in its own way. The network strategy emphasizes the humanity principle over sovereignty, whereas the negotiation strategy is characterized by the primacy of the sovereignty principle. Figure 1 depicts the explanatory dimensions for the emergent strategy.

As far as the legal dimensions of the strategic responses are concerned, our study shows that humanitarian professionals weighed the conflicting principles differently, dependent on the local context in which their mission was set, what type of organization they mostly engaged with, and their trust in local go-betweens. We make a connection between the use of law within an emergent strategic response and the context in which the response takes place. That is, we show that the legal principles are not unambiguously applied within the same conflict, but are prioritized differently. Indeed, in this context of conflicting international legal principles, Shaffer and Pollack (2011) heed warnings that "softening" of hard law can lead to legal ambiguity and confusion. Indeed, in our cases we saw that there was more

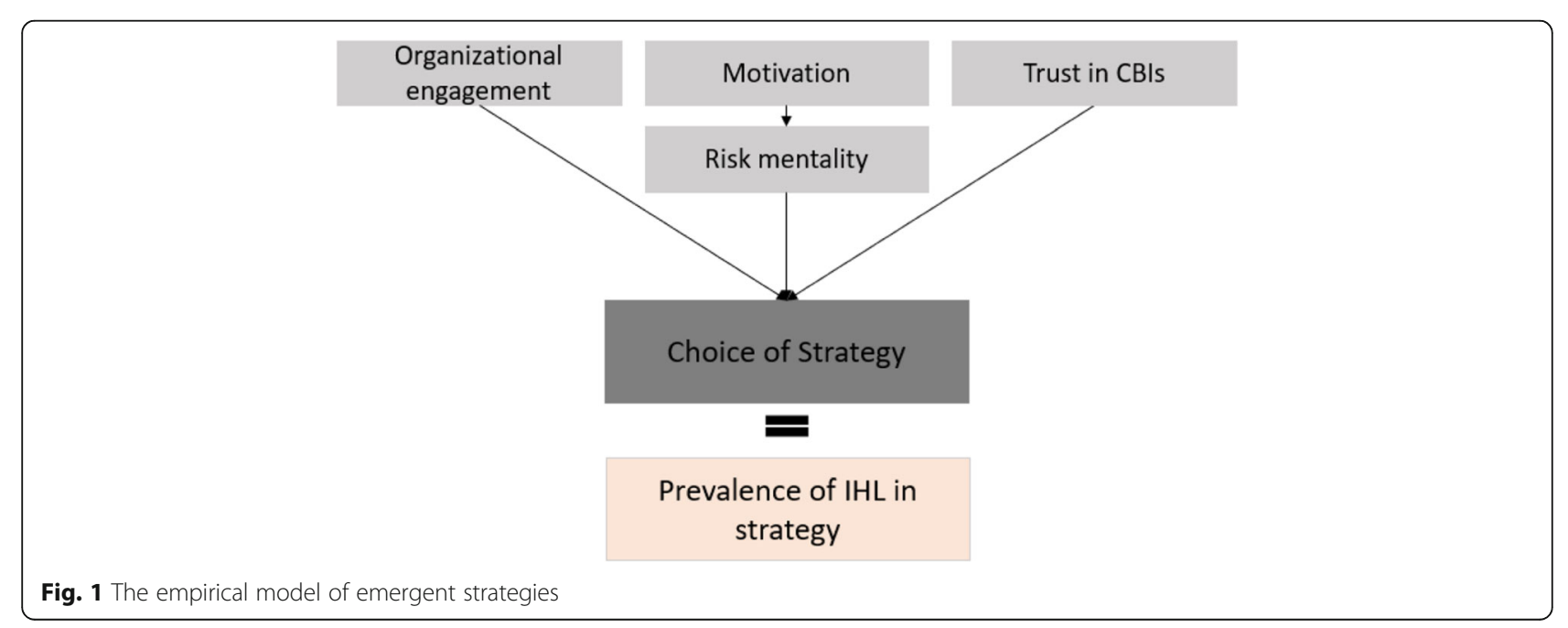


room for professionals' own interpretation to do what they estimated as the just way to proceed, thereby shaping emergent strategies.

Through our study, we provide a deeper understanding of a conflict context by analyzing how humanitarian professionals strategically respond to the tension that emerges between the sovereignty principle and IHL principles, in view of legal and ethical considerations. More specifically, we revealed that IHL principles vis-àvis the sovereignty principle are differentially weighed within the emergent network and negotiation strategies, based on four conceptually distinct dimensions (see Fig. 1 above).

These findings can be explained by drawing on several organizational perspectives. For instance, our study strengthens Cook's finding, that professionals embedding in (in-)formal organizations is critical for the mobilization of law (Cook 2011). Indeed, we found that where humanitarian professionals had a personal involvement with the conflict, it was more likely that the mission as a formal organization would seek pragmatic solutions that could accommodate their needs, including a mutual understanding of IHL principles.

Moreover, our findings corroborate the institutional perspectives on negotiation dynamics, whereby it has been argued that specific kinds of language-such as legal discourse - can be used as a negotiation mechanism (Mayr 2008; Thornborrow 2014). We found this to be the case in the border closure case, whereby sovereignty was acknowledged by professionals who at the same time drew on this principle to negotiate their way into the denial of access context. Conversely, it has been argued that humanitarian discourse can also play a role in negotiating support (Büthe et al. 2012). This was reflected in both our cases, where professionals settled for suboptimal solutions as a means to bypass denial of access, for instance in the besieged area. In this case, professionals drew on the humanity principle as part of a networking strategy, thereby sometimes connecting and appealing to people of questionable repute as a means to gain access to those most in need. These findings show how the law is sometimes a strategic resource for social struggle (McCann 2006). Further research could enlighten the application of IHL in different institutional settings, such as interactions with civil society organizations regarding humanitarian crisis operations, as a means to establish to what extent an institutional setting influences the use of IHL in humanitarian support operations.

The dimension of trust was related to the amount of risk humanitarian professionals were willing to accept in determining their support, as clearly shown through the emergent network strategy. Trust is "accepting the risks associated with the type of depth and the interdependence inherent in a given relationship" (Sheppard and Sherman 1998), which we clearly saw in our cases. In fact, trust is often associated with risk, for instance in the context of a strategic alliance (Das and Teng 2001), which can be likened to the collaboration between a mission and the local context. Further analysis of this context from a trust perspective could be a fruitful avenue for future research.

Finally, our case study touches upon the scholarly fields of digital humanitarianism (Meier 2015; Mulder et al. 2016), and ICT for development (ICT4D) (Walsham 2017; Ferguson and Soekijad 2016), which analyze the implications of ICT-enabled aid efforts. We add to these fields by showing how ICTs can be instrumental in realizing humanitarian aims while adding a legal perspective. Further analysis of this question is an important line of future research.

This study also has limitations. We acknowledge the modest sample size of the study, which makes the outcomes less generalizable. Moreover, our study uses a sampling technique with a focus on a single organization, with a risk of yielding a homogenous sample, which could influence the outcome of the discerned mechanisms. We also recognize that our snowball selection technique could have resulted in selection biases within the study. For example, this organization hires locals to work for the humanitarian mission, which has implications for its humanitarian strategy, but might not occur in other organizations that could usedifferent hiring strategies. While this is an important specification of the study, we emphasize that this particular study aimed to explore response mechanisms of humanitarian teams toward legal tensions that they encounter, which holds up despite this limitation. Indeed, the results provide an initial inventory of mechanisms and therewith the first steps towards a framework that can be further assessed or expanded upon in future research. Moreover, our research offers the groundwork for further refining of the framework in different humanitarian contexts and in other organizations. Attention to the inclusion of locals and specifically political dissidents in international missions is a particularly interesting line of future research, touching upon organization and political dimensions of strategizing.

\section{Implications}

This study contributes to the scholarly domain of international humanitarian studies by collecting the fields of law and organization science as a means to explain humanitarian strategies in practice. Organizational strategy from a practice perspective provides an explanation for the different weighing of IHL principles according to their context. Given the salience of organizations and 
professionals in making IHL efficacious in practice, the lack of prior organizational attention to this domain is surprising. Moreover, the alleviation of suffering is an international community priority, therefore, a better understanding of the interplay between strategic practices by professionals and IHL principles is essential. This study is a first attempt to elucidate this process.

Besides the theoretical implications, this study yields an important practical implication. Namely, humanitarian organizations can take away from this study that engaging locals in a mission can enable remote humanitarian support, but can also lead to excessive risk-taking and can also jeopardize the impartiality principle, due to their personal engagement in the conflict. Seeking a balance in terms of locals and (foreign) professionals can diminish these risks and ensure that the different IHL principles are adequately considered, avoiding the risk of becoming activists rather than a humanitarian organization providing much-needed crisis support.

\section{Conclusion}

This study was guided by the research question: how do humanitarian professionals strategically respond to contemporary conflict in a local context, at the interface between sovereign law and IHL principles? Our case studies of a besieged area and a border closure case revealed that humanitarian professionals engaged two emergent network and negotiation strategies. We identified four dimensions of organizational engagement, motivation, mentality, and trust to explain how humanitarian professionals differentially adopted these strategies and thereby fostered IHL principles. Through our study, we connect the fields of international humanitarian law and organization studies, which is of importance given the critical implications of professionals' strategic choices on the success of humanitarian efforts in conflict situations. Moreover, we shed light on the tension between sovereign law and international humanitarian law, a fascinating field of inquiry that calls for further research. This study represents a step forward in the development of this field.

\section{Abbreviations \\ CBI: Community-based initiatives; ICT: Information and Communication Technology; ICRC: International Committee of the Red Cross; IHL: International Humanitarian Law; UNHCR: United Nations High Commissioner for Refugees}

\section{Acknowledgements}

We acknowledge the valuable support of our respondents, without whom this research would not have been possible. We also recognize the support of Wouter Werner of Vrije Universiteit Amsterdam Law Faculty in developing the research idea.

\section{Authors' contributions}

Each author made a substantial contribution to the development of this journal article and all the authors read and approved the final manuscript.
Authors were involved as follows: E.B and J.F developed the conceptual aspects of the paper; E.B conducted the interviews and analyzed the findings; J.F and P.G supervised the entire process; J.F helped write and edit the paper; a critical review was done by J.F, P.G and K.B. All authors read and approved the final manuscript.

\section{Author information}

Erwin Biersteker (corresponding author) is a PhD student at Vrije Universiteit Amsterdam, Department of Organization Sciences. His research interest includes the governance of temporary organizations. Erwin has Masters degrees in International Law and in Organization Sciences.

Julie Ferguson (PhD, Business Administration) is Senior Researcher at the Center of Expertise Urban Governance and Social Innovation, Faculty of Social Sciences and Law at the Amsterdam University of Applied Sciences. Her main research interest is social network dynamics in a context of social innovation.

Peter Groenewegen is Emeritus Professor at the Department of Organization Sciences, Vrije Universiteit Amsterdam. His research interests are institutional theory, social networks, interorganizational collaboration in innovation, emergencies and health care.

Kees Boersma is an Associate Professor at Vrije Universiteit Amsterdam, Department of Organization Sciences. His research interest is in organizational change and innovation in crisis management and disaster studies. Homepage: www.keesboersma.com

\section{Funding}

This study was supported by a Network Institute Academy Assistant research grant.

\section{Availability of data and materials}

Due to individual privacy conditions and the sensitivity of materials, the datasets used and analyzed for this study are available from the corresponding author only upon reasonable request.

\section{Declarations}

\section{Competing interests}

The authors declare that they have no competing interests.

\section{Author details}

'Department of Organization Sciences, Vrije Universiteit Amsterdam, Amsterdam, The Netherlands. ${ }^{2}$ Center of Expertise Urban Governance and Social Innovation, Faculty of Social Sciences and Law at the Amsterdam University of Applied Sciences, Amsterdam, The Netherlands.

Received: 18 May 2020 Accepted: 30 May 2021

Published online: 17 June 2021

\section{References}

Abdelmagid N, Checchi F, Garry S, Warsame A (2019) Defining, measuring and interpreting the appropriateness of humanitarian assistance. J Int Humanitarian Action 4(1):14. https://doi.org/10.1186/s41018-019-0062-y

Atkinson R, Flint J (2001) Accessing hidden and hard-to-reach populations: Snowball research strategies. Soc Res Update 33(1):1-4

Bartels R (2018) The Relationship between International Humanitarian Law and the Notion of State Sovereignty. J Confl Secur Law 23(3):461-486. https://doi. org/10.1093/jcsl/kry021

Beeckman K (2015) From fundamental principles to individual action: making the principles come alive to promote a culture of non-violence and peace. Int Rev Red Cross 97(897-898):263-293. https://doi.org/10.1017/S181638311 5000569

Boersma K, Ferguson J, Mulder F, Wolbers J (2016) Humanitarian response coordination and cooperation in Nepal. Coping with challenges and dilemmas. Vrije Universiteit Amsterdam, Amsterdam

Boin A, Lodge M (2016) Designing resilient institutions for transboundary crisis management: a time for public administration. Public Adm 94(2):289-298. https://doi.org/10.1111/padm.12264

Bowen GA (2006) Grounded theory and sensitizing concepts. Int J Qual Methods 5(3):12-23. https://doi.org/10.1177/160940690600500304

Broussard G, Rubenstein LS, Robinson C, Maziak W, Gilbert SZ, DeCamp M (2019) Challenges to ethical obligations and humanitarian principles in conflict 
settings: a systematic review. J Int Humanitarian Action 4(1):15. https://doi. org/10.1186/s41018-019-0063-x

Browne K (2005) Snowball sampling: using social networks to research nonheterosexual women. Int J Soc Res Methodol 8(1):47-60. https://doi.org/10.1 080/1364557032000081663

Büthe T, Major S, De Mello e Souza A (2012) The politics of private foreign aid: humanitarian principles, economic development objectives, and organizational interests in NGO private aid allocation. Int Organ 66(4):571607. https://doi.org/10.1017/S0020818312000252

Cardia IV, Holzer A, Xu Y, Maitland C, Gillet D (2017) Towards a principled approach to humanitarian information and communication technology. In: Proceedings of the Ninth International Conference on Information and Communication Technologies and Development, 2017, pp 1-5

Clarke PK, Campbell L (2020) Decision-making at the sharp end: a survey of literature related to decision-making in humanitarian contexts. J Int Humanitarian Action 5(1):1-14

Comfort LK (2007) Crisis management in hindsight: Cognition, communication, coordination, and control. Public Adm Rev 67:189-197. https://doi.org/1 0.1111/j.1540-6210.2007.00827.x

Cook ML (2011) "Humanitarian aid is never a crime": Humanitarianism and illegality in migrant advocacy. Law Soc Rev 45(3):561-591

Das TK, Teng B-S (2001) Trust, control, and risk in strategic alliances: An integrated framework. Organ Stud 22(2):251-283. https://doi.org/10.1177/01 70840601222004

Duffield M (2016) The resilience of the ruins: towards a critique of digital humanitarianism. Resilience 4(3):147-165. https://doi.org/10.1080/21693293.2 016.1153772

Eisenhardt KM (1989) Building theories from case study research. Acad Manag Rev 14(4):532-550. https://doi.org/10.5465/amr.1989.4308385

Eisenhardt KM, Graebner ME (2007) Theory building from cases: opportunities and challenges. Acad Manag J 50(1):25-32. https://doi.org/10.5465/amj.2 007.24160888

Fast $L$ (2015) Unpacking the principle of humanity: Tensions and implications. Int Rev Red Cross 97(897-898):111-131. https://doi.org/10.1017/S181638311 5000545

Ferguson JE, Soekijad M (2016) Multiple interests or unified voice? Online communities as intermediary spaces for development. J Inf Technol 31(4): 358-381. https://doi.org/10.1057/jit.2015.25

Gasser H-P (1998) International humanitarian law and the protection of war victims. International Committee of the Red Cross, Geneva

Gioia DA, Corley KG, Hamilton AL (2013) Seeking qualitative rigor in inductive research: Notes on the Gioia methodology. Organ Res Methods 16(1):15-31. https://doi.org/10.1177/1094428112452151

Gómez MV, Kuronen M (2011) Comparing local strategies and practices: recollections from two qualitative cross-national research projects. Qual Res 11(6):683-697. https://doi.org/10.1177/1468794111413366

Hantrais L (1999) Contextualization in cross-national comparative research. Int J Soc Res Methodol 2(2):93-108. https://doi.org/10.1080/1364557992 95078

Henckaerts JM, Doswald-Beck L (2005) Customary International Law, vol 1. ICRC/. Cambridge: Cambridge University Press

International Committee of the Red Cross (ICRC) (2015) International Humanitarian Law: Answers to your questions. Focus: Geneva

International Court of Justice (ICJ) (1986) Military and paramilitary activities in and against Nicaragua (Nicar. v. U.S)

Jegers M (2002) Review of "Strategic Management for Voluntary Nonprofit Organizations", by Roger Courtney. Volunt Int J Volunt Nonprofit Org 13(4): 432-434. https://doi.org/10.1023/A:1022079024259

Jeong H-W (2005) Peacebuilding in postconflict societies: strategy and process. Lynne Rienner, Boulder

Johnson G, Melin L, Whittington R (2003) Micro strategy and strategizing: towards an activity-based view. J Manag Stud 40(1):3-22. https://doi.org/1 0.1111/1467-6486.t01-2-00002

Kaldor M (2012) New and old wars: Organised violence in a global era. Polity Press, Cambridge

Kapucu N, Arslan T, Demiroz F (2010) Collaborative emergency management and national emergency management network. Dis Prev Manag Int J 19(4):452468. https://doi.org/10.1108/09653561011070376

Kyazze AB (2015) Walking the walk: evidence of principles in action from Red Cross and Red Crescent National Societies. Int Rev Red Cross 97(897-898): 211-233. https://doi.org/10.1017/S1816383115000582
Labbé J, Daudin P (2015) Applying the humanitarian principles: Reflecting on the experience of the International Committee of the Red Cross. Int Rev Red Cross 97(897-898):183-210. https://doi.org/10.1017/S1816383115000715

Labonte MT, Edgerton AC (2013) Towards a typology of humanitarian access denial. Third World Q 34(1):39-57. https://doi.org/10.1080/01436597.2012.755015

Leander A (2005) The market for force and public security: the destabilizing consequences of private military companies. J Peace Res 42(5):605-622. https://doi.org/10.1177/0022343305056237

Mac Ginty R, Richmond OP (2013) The local turn in peace building: a critical agenda for peace. Third World Q 34(5):763-783. https://doi.org/10.1080/0143 6597.2013.800750

Mačák K (2015) A matter of principle (s): The legal effect of impartiality and neutrality on States as humanitarian actors. Int Rev Red Cross 97(897-898): 157-181. https://doi.org/10.1017/S1816383115000661

Maisel N (2015) Strange bedfellows: Private military companies and humanitarian organizations. Wis Int Law J 33:639-666

Malantowicz A (2013) Civil war in Syria and the new wars debate. Amsterdam Law Forum 5(3):52-60. https://doi.org/10.37974/ALF.260

Marshall MN (1996) Sampling for qualitative research. Fam Pract 13(6):522-526. https://doi.org/10.1093/fampra/13.6.522

Mayr A (2008) Language and power: an introduction to institutional discourse. Continuum International Publishing Group, London

McCann M (2006) Law and social movements: contemporary perspectives. Annu Rev Law Soc Sci 2(1):17-38. https://doi.org/10.1146/annurev.lawsocsci.2.081 805.105917

Meier P (2015) Digital humanitarians: How big data is changing the face of humanitarian response. Routledge, Abingdon. https://doi.org/10.1201/b18023

Morrison JB, Salipante P (2007) Governance for broadened accountability: blending deliberate and emergent strategizing. Nonprofit Volunt Sect Q 36(2):195-217. https://doi.org/10.1177/0899764006295992

Mulder F, Ferguson J, Groenewegen P, Boersma K, Wolbers J (2016) Questioning Big Data: Crowdsourcing crisis data towards an inclusive humanitarian response. Big Data Soc 3(2):2053951716662054

Newman E (2014) The United Nations and human security: between solidarism and pluralism. In: Martin M, Owen T (eds) Routledge Handbook of Human Security. Routledge, London, pp 225-238

Ogliastri E, Jäger UP, Prado AM (2016) Strategy and structure in high-performing nonprofits: Insights from Iberoamerican cases. Volunt Int J Volunt Nonprofit Org 27(1):222-248. https://doi.org/10.1007/s11266-015-9560-8

Pictet J (1979) The fundamental principles of the Red Cross. Int Rev Red Cross Arch 19(210):130-149. https://doi.org/10.1017/S0020860400019872

Raymond NA, Card BL (2015) Applying humanitarian principles to current uses of information communication technologies: Gaps in doctrine and challenges to practice. In: Signal Program on Human Security and Technology. Harvard Humanitarian Initiative

Shaffer GC, Pollack MA (2011) Hard versus soft law in international security. Boston Coll Law Rev 52:1147-1242

Sheppard BH, Sherman DM (1998) The grammars of trust: a model and general implications. Acad Manag Rev 23(3):422-437. https://doi.org/10.5465/amr.1 998.926619

Starbird K, Palen L (2011) "Voluntweeters" self-organizing by digital volunteers in times of crisis. In: Proceedings of the SIGCHI conference on human factors in computing systems, 2011, pp 1071-1080

Starr MK, Van Wassenhove LN (2014) Introduction to the special issue on humanitarian operations and crisis management. Prod Oper Manag 23(6): 925-937. https://doi.org/10.1111/poms.12227

Thornborrow J (2014) Power talk: language and interaction in institutional discourse. Routledge, London. https://doi.org/10.4324/9781315839172

Vaara E, Whittington R (2012) Strategy-as-practice: taking social practices seriously. Acad Manag Ann 6(1):285-336. https://doi.org/10.5465/19416520.2012.672039

Walsham G (2017) ICT4D research: reflections on history and future agenda. Inf Technol Dev 23(1):18-41. https://doi.org/10.1080/02681102.2016.1246406

Wolbers J, Ferguson J, Groenewegen P, Mulder F, Boersma K (2016) Two faces of disaster response: transcending the dichotomy of control and collaboration during the Nepal earthquake relief operation. Int J Mass Emerg Disasters 34(4):419-438

\section{Publisher's Note}

Springer Nature remains neutral with regard to jurisdictional claims in published maps and institutional affiliations. 